\title{
Perceived Helicopter parenting and its relation with decision making styles and academic performance in the context of Indian adolescents
}

\author{
Medhavi Sood*, Dweep Chand Singh** \\ * P.D. (Cl. Psy), CRR- A52505, Psy.D. Scholar \& Corresponding author, Amity Institute of Behavioural Health and Allied Sciences (AIB(H)AS), \\ Amity University, NOIDA. \\ ** Professor and Director/Head AIB(H)AS Amity University Uttar Pradesh, NOIDA
}

DOI: 10.29322/IJSRP.11.05.2021.p11323

http://dx.doi.org/10.29322/IJSRP.11.05.2021.p11323

\begin{abstract}
Introduction: Helicopter parenting (HP) refers to a distinct type of perceived parenting. It is developmentally inappropriate levels of parent involvement and control in their children's lives, which is often observable through their advice, direction, and help with problem. They even make decisions for their children and personally invest in their children's goals. Today's adolescents are expected to make decisions pertaining to their health related behaviour and career related choices. Decision making refers to the capability of developing reliable level of competence to foresee the consequences of alternatives. It is the fourth phase of cognitive development which is normally reached during adolescence, and is synonymous with abstract thinking, logical reasoning and problem-solving skills. Helicopter parenting has been shown to have negative outcomes in emerging adults but so far it has not been investigated in adolescents in India.

Methods: This was a cross-sectional, correlational designed study to assess the relationship of Helicopter Parenting with Decision Making styles of Adolescents and their academic performance. Secondary objectives were to ascertain the effect of adolescents' variables on decision making styles and Helicopter parenting scores. A sample size of 425 adolescents was taken.

Results: The mean HP scores were higher than the western scores. HP showed a significant correlation with Maladaptive decision making styles, with HP being a good predictor for maladaptive decision making in adolescents, $\left(\mathrm{R}^{2}=.077, \mathrm{~F}(1,423)=\right.$ $35.086, \mathrm{p}=.000$. There was no significant correlation with ADMQ Adaptive type but showed a good linear model with self-esteem subscale. There was no statistical significant effect of adolescent's age on HPS.
\end{abstract}

There was a significant negative correlation of HP scores with above average academic performance $(0.115, \mathrm{p}=0.017)$ and with total scores $(0.106, \mathrm{p}=0.029)$. Academic performance was a good negative predictor for HP $\left(\mathrm{R}^{2}=0.011, \mathrm{~F}(1,424)=4.800\right.$, $\mathrm{p}=0.029$ ).

Conclusions: Indian adolescents score high on HP scale. However Indian adolescents prefer not to strongly agree on HPS items and rather remain more non-decisive with mean score of 3.559. We also found that higher HPS score predicts maladaptive decision making style and negatively predicts self-esteem subscale of adaptive decision making styles.
Implications: We need to educate the parents about the detrimental effects of helicopter parenting in order to have more self reliant adolescents.

Index Terms- Helicopter parenting (HP), Helicopter Parenting Scale (HPS), Decision making styles, ADM-Q, adaptive, maladaptive

\section{INTRODUCTION}

$\mathrm{P}$ arent child relationship is the most important relationship in a child's life and has been of interest for the Developmental psychologists. Parenting styles from parent's perspective have also been extensively researched but understanding child's perspective of their parent's behaviour is a better way to understand child's behaviour. The term Helicopter parenting (HP), was first used in Cline and Fay's parenting book series and subsequently made popular by a Newsweek article[1,2]. It is a distinct type separate from the four categories of Parenting styles' defined by Baumrind (1967) and Maccoby (1983), i.e. Authoritative, Authoritarian, Permissive and Neglectful [3]. Cline and Fay explained that helicopter parents behave this way because "they confuse love, protection, and caring" by not allowing their child to fail in any aspect of their child's life [2]. HP refers to overly involved and overprotective parents who communicate with their children constantly, intervene in their day to day children's affairs, and remove obstacles from their children lives. They even make decisions for their children and personally invest in their children's goals $[4,5,6]$. According to Padilla-Walker, Helicopter parenting denotes a specific dimension of parenting, these parents are high on warmth/support, control, and low on granting autonomy. This way HP appears to involve the same major dimensions of parenting (e.g., responsiveness/involvement, control, and autonomy granting) that comprise other forms of parenting (e.g., authoritative parenting, psychological control), however HP is unique in the context of prioritizing these dimensions. HP can said to be different from other types, being low on psychological control, as it does not target psychological or emotional autonomy of the child. Although it does reflect some aspects of behavioral control, along with high warmth and support and exercising unnecessary limits of autonomy that are not at all 
age appropriate for the child [5]. HP represents normative parenting taken to dysfunctional level [4].

HP is also reported to be associated with a lower academic achievement [7, 8]. HP was found to be associated with poorer functioning in emotional functioning, decision making, and academic functioning [9]. One of the apparent consequences of HP in attempting to solve all of their children's problems and even assume responsibility for their child's well-being well into adulthood is that the child never develops a strong belief in his or her own ability to solve problems and achieve goals. But unlike some other maladaptive parenting practices such as abuse, HP is defined in a matter of degree. Over parenting/HP and authoritarian parenting both reflect deficits in knowing as to know when to back off and allow for some self-direction on the part of the child. This process is particularly true when that direction is at odds with the parent's own opinion or perspective. HP can thus be seen as a failure to adapt to the changing and diminishing needs of the aging child. This projection of parents' needs and desires on to their children is a form of enmeshment in which affective connections may be too strong and boundaries too vague for the family's own good. These may affect child's risk aversion, a preoccupation with the child's happiness, and the drive to solve problems for the child, perhaps before they even develop [6].

HP has been studied mainly among the emerging adults, primarily college students, but research also indicates its influence on a child's development at a much earlier phase than emerging adulthood $[4,10]$.

Adolescence is a critical stage between childhood and adulthood. It is also an important transition when an individual moves from dependency on and attachment to their parents to a stage when he or she searches for self-identity, independence, intimacy, and connections with the outside world [11]. The development of autonomy is found to be closely linked to identity formation and is also generally conceptualized primarily as either a psychological or an interpersonal process, If individuals develop a high sense of agency, i.e. taking responsibility for their own actions while retaining close connections with significant adults, they are likely to develop a healthy "autonomous, relational self," which is likely to result in relatively low risk-taking [12,13].]

Piaget proposed a four-phase perspective on cognitive development; the sensorimotor, preoperational, concrete operations and formal operations phases. This fourth phase of formal operations is reached usually during adolescence. It comprises of abstract thinking, logical reasoning and problemsolving skills that are important in making decisions [14] Decision making research has focused primarily on decisional processes deemed normative, and often failed to consider alternative processes or approaches to decision making [15].

Usually the capability of developing reliable level of competence to foresee the consequences of alternatives develops by 15 years of age. Prior to this age they are incapable of creating options that foresee the consequences of alternatives [12, 16]. This is based on Janis and Mann's theory, concerning decision making styles and self confidence $[16,17]$. Their theory is reflected in the five subscales of the ADM-Q, namely self-confidence, vigilance, panic, evasiveness and complacency. These five subscales into two categories, 'adaptive' and 'maladaptive' decision making patterns. An adaptive pattern is carefully deliberated behaviour, such as vigilant and self-confident decision making. A maladaptive pattern, on the other hand, fails to meet many of the requirements of high quality information processing. Panic, evasiveness and complacency are a spectrum of maladaptive decision making patterns.

Parenting has been found to also nurture the development of certain decisional making styles in children and adolescents [18]. In addition, the way in which adolescents develop their decision making is often based on their parents' decision making strategies [19].

This study was aimed at finding the prevalence of perceived helicopter parenting and its relation with academic performance and decision making among Indian urban young and middle adolescents. All the previous researches have focused on the perceptions of the children when they were growing up but this study aimed to focus on the present context, i.e. while growing up.

\section{Methods}

The study was conducted as a cross-sectional, correlational study designed to assess the relationship of Helicopter Parenting with Decision Making of Adolescents and academic performance. Secondary objectives were to to ascertain the effect of gender and age of adolescents and parent's variables on Helicopter parenting scale. A sample size of 425 adolescents was calculated. Purposive sampling technique was used for data collection. The inclusion criteria were adolescents aged 13 years-17 years, residing in Delhi and NCR , and studying in English medium schools. Students living alone or in hostels and any prior diagnosis of a psychiatric, medical, or neurological illness/disability were the exclusion criteria. The sample was collected through school principals, class teachers, private tuition centers, adolescents' parents, and adolescents from Delhi and NCR, after taking informed consent. The data was collected using the basic information in Personal information sheet and the following tools:

\section{Helicopter Parenting Scale (HPS) by Terri LeMoyen and} Tom Buchanan (2011) [4]

It is a 7 item scale used to assess Helicopter Parenting. Scoring of this scale suggests the presence or absence of helicopter parenting. This scale has been used in a wide range of researches to establish a relationship between helicopter parenting and other variables such as mental health, self-efficacy [17].parental control, academic problems, suicidal ideas, etc. [20]. LeMoyen and Buchanan (2011) view helicopter parenting as a single construct Helicopter Parenting Scale is a \& item scale that is scored on a 6 point Likert scale ranging from strongly agree (6) to strongly disagree (1) to be done by the adolescents. Scoring is done by adding the scores of the 7 items and dividing them by 7 (number of items). It has a Cronbach's alpha of 0.71 . Permission to use this scale was received from the authors of this scale.

\section{Adolescent Decision-Making Questionnaire (ADM-Q)} by Leon Mann et. al. (1988) [16]

It is a scale used to assess which decision making strategy adolescents use when it comes to making a decision. This scale has been used in a vast variety of researches to establish its relationship with various variables such as gender, educational level/grade in which adolescent is studying, self-confidence, social pressures [12], self-esteem [16]. 
ADM-Q is a questionnaire with 30 items divided into 5 subscales namely decision self-esteem, vigilance, panic, a cop-out, and complacency. The subscale cop-out is further divided into 3 subscales namely defence avoidance, put off, and pass on. It is rated on a 4 point Likert scale ranging from not at all true for me (0) to almost always true for me (3) to be done by the adolescents. Scores are summed to get a score for each scale. Higher scores in a particular subscale indicated that particular strategy is being used more often. It has a Cronbach's alpha of reliability of 0.60 to 0.76 on different subscales. It has also been validated for the Netherlands's adolescents with a good reliability. Permission to use this scale was received from the authors of this scale.

Ethical Approval: The research was approved by the Amity Institute of Behavioral (Health) and Allied Sciences Departmental Research Committee and Amity University Ethics Committee. All participants were provided with a consent form following Helsinki Good Clinical guidelines.

The voluntary nature of the adolescent participation was ensured. They were free to withdraw at any point of time during the study. Data were collected both offline and online owing to ongoing covid pandemic. Out of 453 participants, parents of 18 adolescents refused to consent for the adolescent's participation and 11 were excluded following the exclusion criterion.

After they consented to the study, they were then asked to fill in the basic information in Personal information sheet, which included the information about their parents. Once that was complete, they were given questionnaires on helicopter parenting and decision making. The session took approximately 10-15 minutes.

The data was analyzed using the Statistics Package for the Social Sciences (SPSS) version 20.0. Descriptive and inferential statistics were used. Dummy variables were created wherever required .Bivariate correlation was used to assess the direction and magnitude between Helicopter parenting, and ADMQ (decision self-esteem, vigilance, panic, a cop-out, complacency, defense avoidance, put off and pass on).Regression analysis was conducted to determine the effect of predictor variables on outcome.

\section{$\underline{\text { Results }}$}

The mean age of the 425 participants, was 15.08 years, $S . D=$ 1.50.A total of $174(40.9 \%)$ adolescents were in less than 15 years group, and 251(59.1\%) were in middle adolescence, i.e. more than 15 years. Girls constituted $\mathrm{n}=235(55.3 \%)$ and boys were $\mathrm{n}=190(44.7 \%)$.

The mothers were mostly homemakers $n=279(65.6 \%)$ and $\mathrm{n}=146(34.4 \%)$ were working professionals. Fathers were mainly businessmen $n=154(36.2 \%)$, working non-professionals, $n=143$ $(33.6 \%)$, and professionals as lawyers, doctors, teachers and managers, $\mathrm{n}=128(30.1 \%)$.

Overall HPS scores were $\mathrm{M}=3.559$, $\mathrm{S} . \mathrm{D}=0.523$. Using sample mean of the population i.e. $3.559,184$ adolescents $(43.3 \%)$ scored above this cut off. Using the author's criteria of presence or absence of perceived helicopter parenting as score of 4 , being cutoff, a total of 100 adolescents $(23.5 \%)$ scored above 4 .

There was no statistically significant difference when comparison between young and middle adolescents was made [in young adolescents, less than 15 years $n=174$, mean $\mathrm{HPS}=3.533$,
$\mathrm{S} . \mathrm{D}=0.533$; for middle adolescents more than 15 years $\mathrm{n}=251$, mean HPS $=3.577, \mathrm{~S} . \mathrm{D}=0.479,[\mathrm{t}(423)=-0.853, \mathrm{p}=0.394$, $\mathrm{F}=0.407]$.

There was no significant gender difference for HPS scores [females $\mathrm{n}=235$, mean $=3.562, \mathrm{~S} . \mathrm{D}=0.557$; males $\mathrm{n}=190$, mean $=$ 3.556, $\mathrm{S} . \mathrm{D}=0.479,[\mathrm{t}(423)=0.116, \mathrm{p}=0.908 \mathrm{~F}=4,325]$.

No significant correlation with order of birth and number of siblings or single child was seen. Although there was a negative correlation with being single born $(-0.080, \mathrm{p}=0.099)$ or first born $(0.021, \mathrm{p}=0.664)$

The HPS scores according to the father's profession were: Professionals $\mathrm{n}=128$, mean $\mathrm{HPS}=3.513$, $\mathrm{S} . \mathrm{D}=0.490$; business $\mathrm{n}=154$, mean $\mathrm{HPS}=3.550, \mathrm{~S} . \mathrm{D}=0.551$; nonprofessional working $\mathrm{n}=143$, mean $\mathrm{HPS}=3.611, \mathrm{~S} . \mathrm{D}=0.521$.

There was no significant correlation of HPS scores by father's occupation, $[\mathrm{F}(2,422)=1.226, \mathrm{p}=0.294]$.

The mean HPS was higher in adolescents with working mothers, (nonworking: $\mathrm{n}=279$, mean $\mathrm{HPS}=3.550$, S.D $=0.495$; working: $n=146$, mean $\mathrm{HPS}=3.576, \mathrm{~S} . \mathrm{D}=0.575)$. There was an insignificant negative correlation of HPS scores with mothers occupation $(-0.023, \mathrm{p}=0.638)$.

The mean HPS scores according to the marks scored were: Below average score: $n=101$, mean HPS $=3.506, S . D=0.551$; average score $n=179$, mean $\mathrm{HPS}=3.609$, $\mathrm{S} . \mathrm{D}=0.475$; above average score, $\mathrm{n}=145$, mean $\mathrm{HPS}=3.535, \mathrm{~S} . \mathrm{D}=0.557$.

There was a significant negative correlation of HPS scores with above average academic performance $(0.115, \mathrm{p}=0.017)$ and with total scores $(0.106, \mathrm{p}=0.029)$. Academic performance was a good negative predictor for HP $\left[\mathrm{R}^{2}=0.011, \mathrm{~F}(1,424)=4.800\right.$, $\mathrm{p}=0.029$ ].

Using $73 \%$ as group academic scores mean, the results were, in less than 73 group mean of academic score, $n=184$, mean $\mathrm{HPS}=3.564$, S.D $=0.520$; and in more than 73 group mean, $\mathrm{n}=241$, mean HPS $=3.556, \mathrm{~S} . \mathrm{D}=0.527,(-0.007, \mathrm{p}=0.891)$.

ADM-Q was assessed on individual subscales as well as two groups of Adaptive (sum of decision self-esteem, vigilance subscales) and Maladaptive (sum of panic, a cop-out, and complacency subscales). Overall mean score of ADM-Q adaptive was: $n=425$, mean $=21.571, S . D=5.253$; Overall mean score of ADM-Q maladaptive was: $\mathrm{n}=425$, mean $=17.725, \mathrm{~S} . \mathrm{D}=6.602$.

ADM-Q adaptive with less than 15 years $n=174$, mean $=21.47701$, $\mathrm{S} . \mathrm{D}=4.944436[\mathrm{t}(423)=-0.309, \mathrm{p}=0.757]$. ADM-Q maladaptive in more than 15 years $\mathrm{n}=251$, mean $=18.03586, \mathrm{~S} . \mathrm{D}=6.841835,[\mathrm{t}$ $(423)=0.369, p=0.713]$. There was a good correlation between ADM-Q subscales and HP Scores (Table-1).

Regression analysis showed ADM-Q Maladaptive with a linear correlation with HPS $\left[\mathrm{R}^{2}=0.077, \mathrm{~F}(1,423)=35.086\right.$, $\mathrm{p}=0.000]$.Regression for HPS with ADM-Q-complacency subscale was $\left[\mathrm{R}^{2}=0.049, \mathrm{~B}=1.396, \mathrm{~F}(1,423) 21.851, \mathrm{p}=0.000\right]$. Regression for HPS with ADM-Q-panic subscale was $\left[\mathrm{R}^{2}=0.065\right.$, $\mathrm{B}=1.619, \mathrm{~F}(1,423)=29.624, \mathrm{p}=0.000]$. Regression for HPS with ADM-Q-defense avoidance was $\left[\mathrm{R}^{2}=0.033, \mathrm{~B}=0.459, \mathrm{~F}(1,423)=\right.$ $14.257, \mathrm{p}=0.000]$.

Regression for HPS with ADM-Q- put-off was $\left[\mathrm{R}^{2}=.034\right.$, $\mathrm{B}=.485, \mathrm{~F} \quad(1,423)=14.794, \mathrm{p}=.000]$. ADM-Q- pass-on was $\left[\mathrm{R}^{2}=.030, \mathrm{~B}=.463, \mathrm{~F}(1,423)=13.266 \mathrm{p}=.000\right]$. However no model fit could be established for total copout sub style.

Regression analysis of ADM-Q Adaptive with HPS showed $\left[\mathrm{R}^{2}=0.002, \mathrm{~B}=-0.481, \mathrm{~F}(1,423)=0.974, \mathrm{p}=0.324\right]$. $(\mathrm{NEGATIVE}=$ 
regression of ADM-Q self-esteem subscale with HPS was $\left[\mathrm{R}^{2}=0.024, \mathrm{~B}=-0.842, \mathrm{~F}(1,423)=10.210, \mathrm{p}=0.002\right]$

Multiple hierarchical regression models are depicted in Tables 25

\section{Discussion}

Helicopter parenting has mainly been studied on emerging adults with limited research on middle adolescents. This research adds to the literature and brings a North Indian perspective of Helicopter Parenting. Similar to the reports in the literature, males have scored slightly higher than females on HPS, although it was not statistically significant $[20,21]$. The middle adolescents i.e. above 15 years scored higher than those below 15 years, suggesting that may be perceived as a normal for that age group, although not statistically significant.

Overall mean score was found to be higher than the original reported by Lemoyne et al., (i.e. our score of 3.559 vs. author's score 2.8 [4].

Using the author's criteria of presence or absence of perceived helicopter parenting as score of 4, being cutoff, a total of 100 adolescents $(23.5 \%)$ scored above 4 . Whereas using our sample mean of the population i.e. 3.559, a total of 184 adolescents (43.3\%) scored above this cut off. this also suggests that Indian adolescents prefer not to strongly agree on HPS items and rather remain more non decisive in agreement with the HPS items.

Thus it can be said that although Indian adolescents score higher on HPS than their western counterparts, albeit emerging adults but do not strongly agree with these helicopter parenting attributes, irrespective of the age. In another study on adolescents in 15-17 years age group the mean HPS scores were not estimated [17].

Most helicopter parents are conceptually well-educated. It is postulated that who have the resources including money, connections and negotiating skills which they may use to overindulge and shelter their children [22]. However in our study the housewife mothers negatively correlated with higher HP scores $(0.006 \mathrm{p}=0.999)$, whereas fathers occupation had no bearing $0.075 \mathrm{p}=0.122$, with HP scores.

Helicopter parenting is found to be a very usual practice in Asia. It begins early starting fetching their children to kindergarten and primary school, to staying off work on their child examination day and even wait at school until the examination is over. This phenomenon usually continues even after their child enters the zone of adolescent. Parents of one-child family tend to hover overhead to watch and protect their child [1]. However it showed no bearing in our study $(\mathrm{p}=0.099)$. Overprotective parents tend to inhibit the capability of being independent in their children thereby unintentionally prevent them from gaining selfconfidence. Studies also revealed that children from helicopter parents tend to be very dependent on external instruction and appraisal [1]. This reflects in the decision making scores in our study too. It can be seen that higher HPS scores correlated significantly with maladaptive decision making and negatively correlated with adaptive decision making. Helicopter parenting was found to be negatively correlating with self-efficacy for learning [17]. They had concluded that parent's ways of nurturing their children has influenced their outcome academic outcome [17]. Similarly we found that being an average scorer in academics showed a positive correlation with perceived HP. Presumably, this overprotective parenting may seem good outwardly for parents and outsiders but produced various ill-intense behavior and psychological issues among adolescents. This finding adds to growing body of literature and expands our knowledge and understanding regarding the notion of helicopter parenting.

Research shows adolescents in East Asian countries are oriented towards complying with what their parents tell them to do. Parallel to this, Pomerantz and Wang's (209) study resulted in the conclusion that Chinese adolescents feel obligated towards what their parents tell them to do, with increasing age, contrary to American adolescents [25]. This explains why the average answer to the HPS question no. 2, (i.e., I sometimes feel that my parents don't feel I can make my own decisions) was slightly agree by most adolescents $(M=3.564, S D=1.341)$; answer to the HPS question no. 6, (i.e. My parents often step-in to solve life problems for me) by most adolescents was agree $(M=4.571, S D=1.179)$. And on ADMQ question no. 10, (i.e. when faced with decisions I go along with what others suggest.) the answer by most adolescents was sometimes true $(M=1.116, S D=0.827)$. Answer by most adolescents on ADMQ question no. 29, (i.e. when making decisions I tend to choose the first alternative that comes to my mind.) was sometimes true $(M=1.120, S D=0.878)$. This indicates that Indian adolescent hesitates before making a decision. The mean score for HPS was $M=3.56$ indicating that adolescents in this study kept going back and forth between Slightly Disagree and Slightly Agree when it came to deciding if they perceived their parenting as Helicopter Parenting. This may indicate their indecisiveness.

Although literature suggests a significant difference between males and females on the subscales of ADMQ but no gender difference was noted and no statistically significant difference was seen on the subscales of ADMQ in the groups above or below 15 years.

Negative correlation of academic scores with HP indicates that adolescent whose academic performance was above average may have a sense of entitlement; however there was no correlation between academic scores and decision making styles. Below average scores also showed put-off and pass on subtypes of maladaptive styles of decision making.

As compared to the Australian population Indian adolescents score low on adaptive decision making subscales and higher on maladaptive subscales [16]. It is further negatively affected by academic performance and home maker mothers. Is it because having a homemaker mother

Thus it can be concluded that even though Indian adolescents don't perceive their parenting as helicopter parenting, there is a significant impact of Helicopter parenting on their decision making which is lowering their self-esteem and increasing their complacency, panic, and cop-out when it comes to making a decision.

When compared with the adolescent population of Turkey (432 girls and 486 boys) ADM-Q subscale scores: Self-esteem $(\mathrm{M}=2.98, \quad \mathrm{SD}=0.49)$, vigilance $(\mathrm{M}=3.13, \quad \mathrm{SD}=0.55), \quad$ Panic $(\mathrm{M}=2.16, \mathrm{SD}=0.63)$, Complacency $(\mathrm{M}=1.75, \mathrm{SD}=0.49)$ and Cop out $(\mathrm{M}=1.80, \mathrm{SD}=0.48$, Indian adolescents have scored much higher scores in ADMQ [23]. In this study males scored significantly higher on self-esteem, complacency, and cop-out as compared to females scoring significantly highly on vigilance and panic [23]. 
In a study conducted on 2603 males and females from multiethnic origin i.e. western, east Asian countries and Spain, using decision-making questionnaire ADM-Q , males scored higher in western countries on self-esteem, vigilance, self-esteem; East Asian countries higher on procrastination (put off), and Spanish higher on self-esteem whereas women scored higher on all the scales[24]. In all these studies using ADM-Q, no relationship was established with HPS scores.

Leubbe et al, found a nuanced pattern of relations between HP and certain decision-making styles. They also suggested that HP was associated with less adaptive decision making, similar to our results. These authors albeit have used a different HP scale [9]. We also found that higher HPS score predicts maladaptive decision making subscales, i.e. complacency, panic and copout and negatively predicts self-esteem subscale of adaptive decision making styles.

Although helicopter parents' hovering behavior is benevolent in nature by intention, but the effects on children are not so. It may result in neuroticism, interpersonal dependency, and coping efficacy thus suggesting that this parenting style is detrimental to children's healthy development and interpersonal relationships. This tendency to intervene and to "save" their children from difficult situations may temporarily alleviate their children's discomfort in the short term, but it eventually impairs their physical, social, and emotional development and wellbeing in the long term. Those children who rely on their helicopter parents' constant assistance in all actions to satisfy their needs or accomplish their goals, experience anxiety or fear in unfamiliar social settings, and lack the confidence and skills to cope with trivial and major life problems [1]. It further relates to their decision making [1]. These negative trends are consistent with the links with dangerous self-destructive child outcomes $[4,6]$.

Behavioral control is one of the characteristics of helicopter parenting and could directly affect student time and effort. If the adolescent's behavior is highly controlled by parents, he or she would be less likely to seek engagement in school, as the parents are the ones taking responsibility for the student's classes, coursework, marks, academic achievements, etc. and this is very common in Indian context. It is also evident that academic scores and Helicopter parenting along with non working mothers act as predictors for maladaptive decision making styles in adolescents. We need to educate the parents about the detrimental effects of helicopter parenting in order to have more self reliant adolescents.

\section{Future Implications}

Although a sizeable population of adolescents has been included in our study, it can further be expanded to asses them on longitudinally. Whether this is a family wide phenomenon or on parents' unique style can also be assessed in future studies. An additional parent's perspective can also be included.

As there is a direct positive correlation of helicopter parenting with maladaptive decision making styles, we need to find strategies to help the adolescents develop an adaptive decision making styles as they are vulnerable to risky behaviors. Making a choice in career related choices and health related issues demand a good vigilant decision making by the adolescents themselves.

We hope that our research helps improve the importance of avoiding this parenting style in the future so that we have a population of adolescents who have a better decision making skills at health issues, career related issues and avoid risk taking behaviour.

\section{REFERENCES}

[1] Cline F, Fay J. Parenting with love and logic: Teaching children responsibility. NavPress Publishing Group; 2020 Sep 8.

[2] Odenweller KG, Booth-Butterfield M, Weber K. Investigating helicopter parenting, family environments, and relational outcomes for millennials. Communication Studies. 2014;65(4):407-25.

[3] Baumrind D. Effects of authoritative parental control on child behavior. Child development. 1966 Dec 1:887-907.

[4] LeMoyne T, Buchanan T. Does "hovering" matter? Helicopter parenting and its effect on well-being. Sociological Spectrum. 2011 Jul 1;31(4):399-418. doi: $10.1080 / 02732173.2011 .574038$

[5] Padilla-Walker LM, Nelson LJ. Black hawk down?: Establishing helicopter parenting as a distinct construct from other forms of parental control during emerging adulthood. Journal of adolescence. 2012 Oct 1;35(5):117790.doi:10.1016/j.adolescence.2012.03.007

[6] Segrin C, Woszidlo A, Givertz M, Bauer A, Taylor Murphy M. The association between overparenting, parent-child communication, and entitlement and adaptive traits in adult children. Family Relations. 2012 Apr;61(2):237-52.doi:10.1111=j.1741-3729.2011.00689.x

[7] Shoup R, Gonyea RM, Kuh GD. Helicopter parents: Examining the impact of highly involved parents on student engagement and educational outcomes. In49th Annual Forum of the Association for Institutional Research, Atlanta, Georgia. Retrieved from http://cpr. iub. edu/uploads/AIR 2009 Jun 1 (Vol. 202009).

[8] Schiffrin HH, Liss M. The effects of helicopter parenting on academic motivation. Journal of Child and Family Studies. 2017 May 1;26(5):1472-80.

[9] Luebbe AM, Mancini KJ, Kiel EJ, Spangler BR, Semlak JL, Fussner LM Dimensionality of helicopter parenting and relations to emotional, decisionmaking, and academic functioning in emerging adults. Assessment. 2018 Oct;25(7):841-57.

[10] Hong JC, Hwang MY, Kuo YC, Hsu WY. Parental monitoring and helicopter parenting relevant to vocational student's procrastination and self-regulated learning. Learning and Individual Differences. 2015 Aug 1;42:139-46. doi:10.1016/j.lindif.2015.08.003

[11] Erikson EH. Identity: Youth and crisis. WW Norton \& company; 1968.

[12] Tuinstra J, Van Sonderen FL, Groothoff JW, Van Den Heuvel WJ, Post D. Reliability, validity and structure of the Adolescent Decision Making Questionnaire among adolescents in The Netherlands. Personality and individual differences. $2000 \mathrm{Feb}$ 1;28(2):273-85.

[13] Leung, J. T. Y., \&Shek, D. T. L. Theories of Adolescent Development: Overview. The Encyclopedia of Child and Adolescent Development,2020.112. doi:10.1002/9781119171492.wecad305

[14] Davids EL, Roman NV, Leach L. Decision making styles: A systematic review of their associations with parenting. Adolescent Research Review. 2016 Mar 1;1(1):69-90

[15] Parker AM, De Bruin WB, Fischhoff B. Maximizers versus satisficers: Decision-making styles, competence, and outcomes. Judgment and Decision making. 2007 Dec 1;2(6):342.

[16] Mann L, Harmoni RO, Power C, Beswick G, Ormond C. Effectiveness of the GOFER course in decision making for high school students. Journal of Behavioral Decision Making. 1988 Jul;1(3):159-68.

[17] Ganaprakasam C, Davaidass KS, Muniandy SC. Helicopter Parenting and psychological consequences among adolescent. International Journal of Scientific and Research Publications. 2018;8(6):378-

[18] Udell W, Bannon Jr WM, McKay MM. Parenting practices and adolescent decision-making: The importance of racial socialization. Social work in mental health. 2008 May 12;6(4):65-79.

[19] Öztürk N, Kutlu M, ATLI A. The Effect of Parents' Attitudes on Adolescents' Decision-Making Strategies. Inonu University Journal of the Faculty of Education (INUJFE). 2011 Aug 1;12(2).

[20] 82..doi.org/10.29322/IJSRP.8.6.2018.p7849

[21] Kukreja, T., \&Chauhan, N. (2016). Hovering, parental control and responsiveness in relation with college adjustment issues among undergraduate residential and non residential. International Journal,2016 
4(7):2133-2143 DOI: 10.21474/IJAR01 of advanced research research article)

[22] OKRAY Z. Helicopter parenting and related issues: Psychological well being, basic psychological needs and depression on university students. Current Research in Education. 2016 Nov 15;2(3):165-73.

[23] Kantrowitz B, Peg T. The fine art of letting go. : As Parents, Boomers Face Their Final Frontier: How to Stand Aside as Their Children Become Independent Adults: Where's the Line between Caring and Coddling?'. Newsweek. 2006 May 1;147(21):48-9.

[24] Cenkseven-Önder F. The influence of decision-making styles on early adolescents' life satisfaction. Social Behavior and Personality: an international journal. 2012 Oct 1;40(9):1523-36.. doi.org/10.2224/sbp.2012.40.9.1523

[25] De Heredia RA, Arocena FL, Gárate JV. Decision-making patterns, conflict sytles, and self-esteem. Psicothema. 2004 Dec 31:110-6.

[26] Pomerantz EM, Wang Q. The role of parental control in children's development in Western and East Asian countries. Current Directions in Psychological Science. 2009 Oct;18(5):285-9.

\section{AUTHORS}

First Author - Author name, qualifications, associated institute (if any) and email address.

Second Author - Author name, qualifications, associated institute (if any) and email address.

Third Author - Author name, qualifications, associated institute (if any) and email address.

Correspondence Author - Author name, email address, alternate email address (if any), contact number.

Tables

TABLE 1 depicting Correlation matrix of HPS with ADM-Q

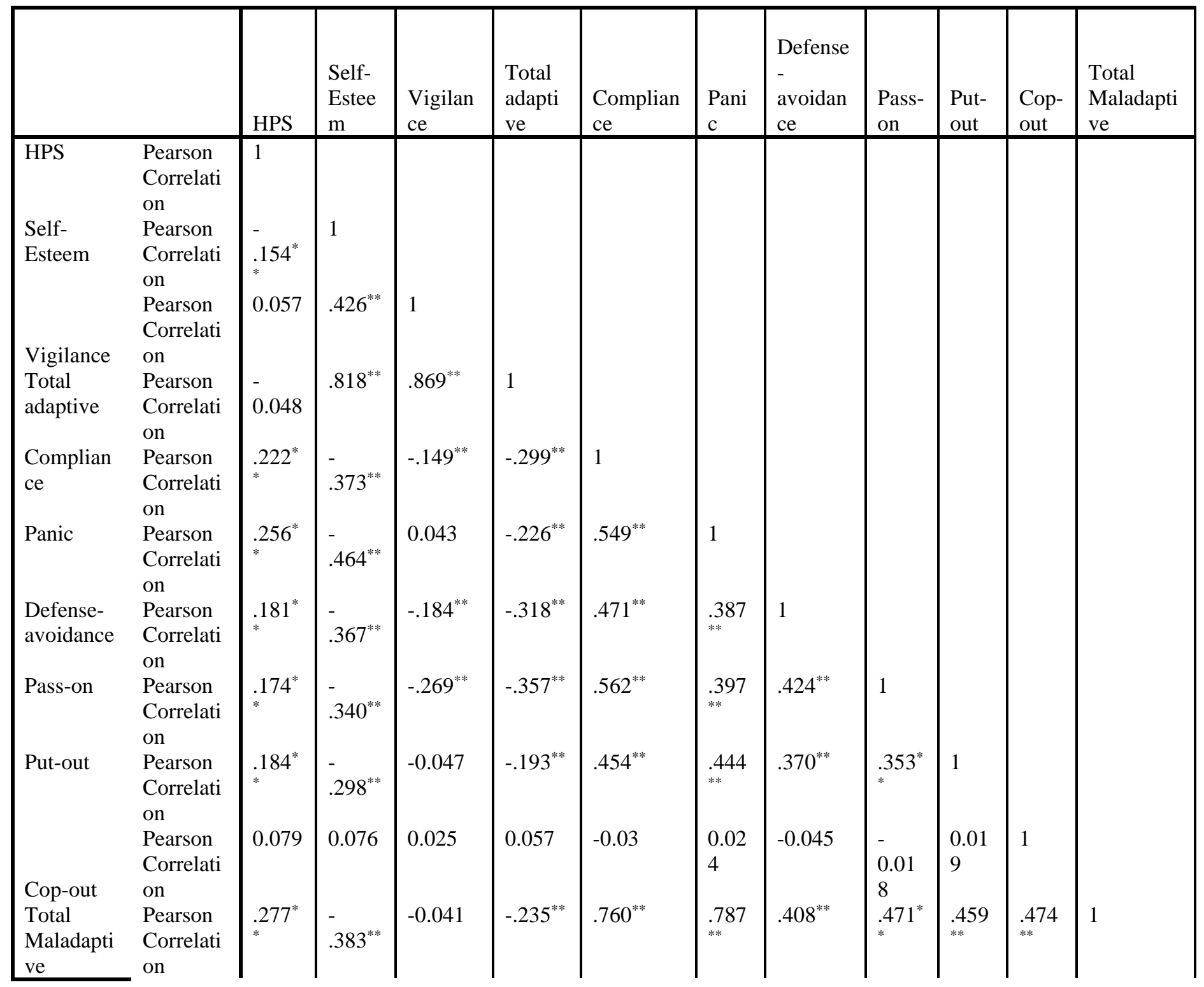


International Journal of Scientific and Research Publications, Volume 7, Issue 8, August 2017 
Table 2: Depicting multiple regression with ADM-Q Adaptive style as dependent variable and Helicopter parenting scores, working or non-working mothers, academic scores, child age

\begin{tabular}{|c|c|c|c|c|c|}
\hline \multicolumn{6}{|l|}{ Variables } \\
\hline DM-Adaptive & B & SE & $\beta$ & $\mathrm{T}$ & $\mathrm{P}$ \\
\hline & 13.988 & 1.116 & & 12.536 & .000 \\
\hline $\begin{array}{l}\text { Constant } \\
\text { HP score }\end{array}$ & & & -.156 & -3.219 & .001 \\
\hline Academic-score & .002 & .007 & .017 & .343 & .732 \\
\hline childageupto15 & .056 & .286 & .010 & .195 & .846 \\
\hline $\begin{array}{l}\text { Mother Working/ } \\
\text { Non-working }\end{array}$ & -.317 & .287 & -.054 & -1.106 & .269 \\
\hline
\end{tabular}

Table 3: Depicting multiple regression with ADM-Q Maladaptive style as dependent variable and Helicopter parenting scores, working or non-working mothers, academic scores, child age less or more than 15 years

\begin{tabular}{llllll}
\hline variables & \multicolumn{1}{l}{} & & & \\
\hline Dm-Maladaptive & $\mathrm{B}$ & $\mathrm{SE}$ & $\mathrm{B}$ & $\mathrm{t}$ & $\mathrm{P}$ \\
\hline (Constant) & 3.930 & 2.482 & & 1.583 & .114 \\
HP score & 3.542 & .592 & .281 & 5.988 & .000 \\
Academic score & -.014 & .015 & -.045 & -.947 & .344 \\
childageupto15 & .404 & .637 & .030 & .635 & .526 \\
Mother W/Nonworking & 1.255 & .638 & .094 & 1.969 & .050 \\
\hline
\end{tabular}

$$
\mathrm{R} 2=.089, \mathrm{~F}=10.204, \mathrm{p}=<0.001
$$

Table 4. : Depicting Regression analysis of ADM-Q Maladaptive style substyle defense -avoidance subcomponent as dependent variable and Helicopter parenting scores, working or non working mothers, below average academic scores and child age less or more than 15 years

\begin{tabular}{|c|c|c|c|c|c|}
\hline \multicolumn{6}{|l|}{ variables } \\
\hline DM Def-avoid & B & SE & $\mathrm{B}$ & $\mathrm{t}$ & $\mathrm{p}$ \\
\hline (Constant) & -.288 & .486 & & -.592 & .554 \\
\hline HP score & .441 & .121 & .174 & 3.649 & .000 \\
\hline $\begin{array}{l}\text { below average } \\
\text { Academic-score }\end{array}$ & & .148 & -.103 & -2.163 & .031 \\
\hline childageupto15 & -.050 & .130 & -.019 & -.385 & .701 \\
\hline mother W/Non & .332 & .130 & .123 & 2.545 & .011 \\
\hline
\end{tabular}

$\mathrm{R} 2=0.058, \quad \mathrm{~F}=6 . \overline{\mathrm{s} 22, \mathrm{p}=<0.001}$ 
Table 5. : Depicting Regression analysis of ADM-Q Maladaptive style substyle put-off subcomponent as dependent variable and Helicopter parenting scores, working or non working mothers, below average academic scores and child age less or more than 15 years

\begin{tabular}{l|ll|l|l|l}
\hline variables & \multicolumn{1}{l}{} \\
\hline DM-Put -Off & $\mathrm{B}$ & \multicolumn{1}{l}{ SE } & $\mathrm{B}$ & $\mathrm{t}$ & $\mathrm{P}$ \\
\hline (Constant) & .346 & .508 & & .682 & .496 \\
HP score average & -.464 & .126 & .176 & 3.671 & .000 \\
$\begin{array}{l}\text { below } \\
\begin{array}{l}\text { Academic-score } \\
\text { childageupto15 }\end{array}\end{array}$ & -.041 & .136 & -.015 & -.300 & .764 \\
mother W/Non & .051 & .136 & .018 & .371 & .711 \\
\hline
\end{tabular}

$\mathrm{R} 2=. \overline{045, \quad \mathrm{~F}=5.003, \mathrm{p}=0.001}$ 